\title{
Scarcity's Enhancement of Desirability: The Role of Naive Economic Theories
}

\author{
Michael Lynn, University of Houston
}

According to psychological research, scarcity increases an object's desirability. Although inconsistent with the assumptions of formal economic theory, this effect of scarcity may be attributable to people's naive (or informal) economic theories. More specifically, scarcity's enhancement of desirability may be mediated by the belief that scarce things are more expensive than available ones. Existing research relevant to this explanation for the effects of scarcity, as well as the implications of this explanation for future research, are discussed.

Scarcity is a fundamental part of economic theory. According to classical microeconomic theory, price in a free market operates as a mechanism for equating supply and demand. Scarcity is a restriction on supply, so market forces raise the price of scarce products until demand for them drops to the available supply level. In this theory, consumer preferences (reflecting the utilities or desirabilities of products) are assumed to be independent of supply. Price goes up with scarcity because scarcity increases competition for a product, not because scarcity increases the product's desirability. Similarly, demand goes down with supply because scarcity prices a product out of the reach of many consumers, not because scarcity decreases the desirability of the product. Thus, according to classical economic theory, scarcity increases market value (or price) and decreases demand (or quantities purchased), but does not affect psychological value (or desirability).

Economists' assumptions about the psychological effects of scarcity are inconsistent with research on commodity theory (Brock, 1968). According to this theory, "any commodity will be valued to the extent that it is unavailable" (p. 246). Much of the research testing commodity theory has operationalized unavailability as scarcity and value as desirability. These studies have found that scarce things are desired more than available things (see Lynn, 1991, for a review). Unfortunately, commodity theory does not explain why this effect occurs; it is a meta-theory that identifies an empirical relationship to be explained by one or more other psychological theories.

Ironically, although scarcity's enhancement of desirability is inconsistent with formal economic theory, it may be at least partly attributable to the general public's naive or informal theories about economics. This possibility is explored here by reviewing: (a) our current knowledge about naive economic beliefs and their relevance to scarcity's enhancement of desirability, (b) existing research 
relevant to this theoretical explanation for scarcity's effects, and (c) the implications of this explanation for future research on scarcity.

\section{Naïve Economic Theories}

The term naive economic theories refers to people's beliefs and expectations about the relationships among economic variables. Relevant variables range from microeconomic variables (e.g., utility, supply, and price) to macroeconomic variables (e.g., gross national product, unemployment, and inflation). The theories about these variables are explicit in the sense that people are able to access the relevant beliefs and report them to others.

Research on naive economic theories has been conducted by psychologists and by marketers. Psychologists have been concerned primarily with understanding how and at what rate people acquire economic concepts and principles (see Furnham \& Lewis, 1986; Lea, Tarpy, \& Webley, 1987; Stacey, 1982; for reviews). In contrast, marketers have tended to focus on people's beliefs about the correlates of product quality and on the impact of these beliefs on information search and product evaluation (see Duncan, 1990, for a brief review). The following inferences can be drawn from this literature:

1. People have a number of beliefs about the relationships among economic variables, but these beliefs may not be accurate or true.

2. People's economic beliefs vary in popularity; some are widely held, whereas others are idiosyncratic.

3. People's economic beliefs are learned from direct experience in the marketplace as well as from formal and informal instruction, but this learning is constrained by the individual's level of cognitive development.

4. People's economic beliefs affect their attitudes and behaviors.

This literature can be related to scarcity's enhancement of desirability by suggesting that the effects of scarcity may be at least partially attributable to people's naive economic theories about scarcity. One specific possibility is that scarcity's enhancement of desirability is mediated by the assumption that scarce things cost more. As already noted, formal economic theory tells us that scarcity increases prices. This message is also conveyed by everyday market experiences (e.g., buying tickets from scalpers) and by public media stories (e.g., those on the increase in gas prices following Iraq's 1990 invasion of Kuwait). Thus, it is plausible that some people have learned to associate scarcity with 
expensiveness. This could explain scarcity's enhancement of desirability as long as people desire expensive things more than inexpensive ones.

There are two reasons why assumed expensiveness may increase the desirability of scarce commodities. First, assumed expensiveness may lead people to attribute higher quality to the commodity. Consumer behavior researchers have found that people believe higher prices are associated with higher quality and that this belief can increase the desirability of expensive products (see Monroe, 1973; Olson, 1974; Rao \& Monroe, 1989; for reviews). Thus, people may apply their naive economic beliefs in a hierarchical fashion - first assuming that a scarce commodity is expensive and then assuming that this expensive commodity is of high quality. Another closely related possibility is that assumed expensiveness creates normative expectations that bias people's perceptions of quality. Seta and Seta's (1982) research on intrapersonal equity theory provides some support for this alternative (see also Seta \& Seta, 1992). Regardless of how it occurs, expensiveness-based attributions of product quality could increase the desirability of scarce goods.

Second, assumed expensiveness may increase the perceived status of scarce commodities. Veblen (1899/1965) argued that people often buy expensive products in order to display their wealth a phenomena he labeled "conspicuous consumption." Although surprisingly little quantitative research has been conducted on this phenomena, researchers have confirmed that people perceive money as a status symbol (Yamauchi \& Templer, 1982). Moreover, Lynn (1990) found that, given a choice of different prices for a product, many people will voluntarily choose to pay more than the necessary minimum, presumably because they want to avoid appearing poor or cheap. These findings suggest that assumed expensiveness might increase the desirability of scarce goods by increasing their status value.

In summary, people's naive economic theories may lead them to assume that scarce things are expensive, and this assumed expensiveness may increase the desirability of scarce commodities by increasing the attributed quality and/or perceived status of the commodities (see Figure 1). This does not mean that scarcity always leads to assumed expensiveness. Many people may not have learned that scarcity increases prices, and this association may not always be salient to those who have learned it. Nor do I want to imply that all scarcity effects on desirability are mediated by assumed expensiveness. Downward social comparison theory (Wills, 1981), need-for-uniqueness theory (Snyder \& Fromkin, 1980), and reactance theory (Brehm, 1966) all describe psychological processes that also produce scarcity effects on desirability. All that I suggest is that assumed expensiveness may mediate some scarcity effects on desirability. 


\section{Empirical Research}

If scarcity's enhancement of desirability is mediated by assumed expensiveness, then several empirical relationships should be obtained. First, people should believe that scarce things cost more than available ones. Second, scarcity on the economic market should enhance desirability more than does nonmarket scarcity. Third, priming thoughts about price should strengthen scarcity's enhancement of desirability. Finally, blocking assumptions about expensiveness should weaken scarcity's enhancement of desirability. Fortunately, research addressing each of these empirical relationships is available. This research is described in the following sections.

Scarcity and Assumed Expensiveness

The model of scarcity effects depicted in Figure 1 (hereafter referred to as the S-E-D model) hypothesized that people have a naive economic theory associating scarcity with expensiveness. Consistent with this hypothesis are the findings of two different sets of studies. In one group of three studies, investigators presented subjects with product descriptions that manipulated the perceived scarcity of the product. Subjects were then asked to indicate how much they thought the product cost. Results of all three studies indicated that subjects considered the commodity more expensive when it was described as scarce than when it was described as available (Atlas \& Snyder, 1978; Lynn, 1989; Verhallen, 1984). These studies demonstrate that people do associate scarcity with expensiveness, but they leave a number of questions about this association unaddressed.

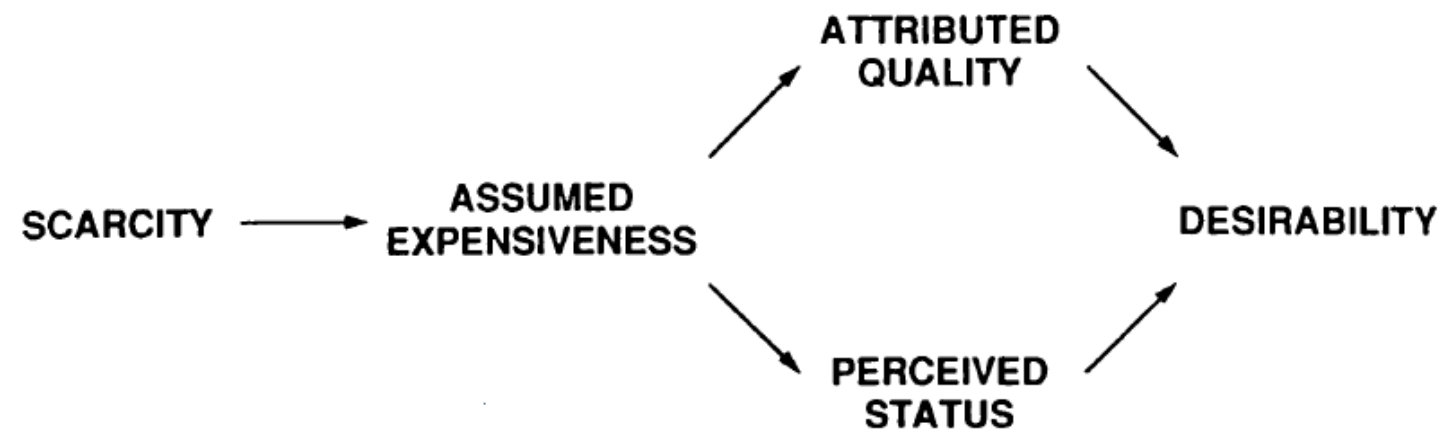

FIGURE 1 The S-E-D model depicting assumed expensiveness, attributed quality, and perceived status as mediators of scarcity's effects on desirability.

It would be interesting to know what percentages of adults believe that scarcity increases prices and at what age this belief is acquired. Fortunately, these issues have been addressed by a second group of studies. Several researchers investigating developmental stages in people's understanding of scarcity 
and/or price have interviewed children and adults about the relationship between these two variables (Fox \& Kehret-Ward, 1985, 1990; Murray, 1980). In this research, from $43 \%$ to $57 \%$ of adult subjects saw scarcity as a source or justification for higher prices, whereas fewer than $8 \%$ of 13 -year-olds did. Although these results should be interpreted with caution because they are based on small and nonrepresentative samples, they do suggest that a large segment of the population has learned that scarcity increases prices and that this lesson is typically learned in late adolescence or early adulthood.

\section{Market versus Nonmarket Scarcity}

If people's naive economic beliefs about scarcity and price are partially responsible for scarcity's enhancement of desirability, then market scarcity should increase desirability more than does nonmarket scarcity. In other words, studies describing marketable products as scarce in the economic market place should produce larger effects than do studies describing marketable products as scarce only within the experimental environment. This is true because people should be good enough economists to know that only market scarcity increases prices.

A recent meta-analysis of the commodity theory literature failed to find support for this hypothesis. When outliers were excluded from the analysis, studies manipulating market scarcity produced no larger effects than those manipulating nonmarket scarcity (Lynn, 1991). However, this was a correlational analysis based on a small number of observations (only four effects for nonmarket scarcity), and it is possible that other differences between the studies were suppressing the expected difference in effect sizes.

A better test of the relative effects of market versus nonmarket scarcity would involve an experimental manipulation of this variable. Verhallen $(1982,1984)$ conducted two such studies. In one study, subjects were shown three recipe books that differed in availability-the experimenter had 6, 16, and 30 copies of each book. The reason for this difference in availability was varied between subjects. They were told either that:

1. The publisher had accidentally sent unequal numbers of the books (accident condition).

2. The subjects in previous studies had chosen some of the books more often than others so different numbers of them remained (popularity condition).

3. The publisher sent smaller numbers of some books because they were printed in smaller editions (limited supply condition).

4. The books differed in popularity among previous subjects and came from different sized editions (popularity plus limited supply conditions). 
After receiving information about the books, subjects were asked to rank order the books from most to least preferred and were told that their top choice would be mailed to them later.

Among subjects who indicated (in a preexperimental questionnaire) that they liked recipe books, preferences for the books were positively related to their scarcity. This effect was observed in all but the accident condition. The accident condition involved nonmarket scarcity, whereas the limited supply and popularity plus limited supply conditions involved market scarcity. The popularity condition did not explicitly involve scarcity in the economic market, but its experimental scarcity was due to a market cause (i.e., demand). Thus, the results of Verhallen's (1982) study provide some support for the greater effectiveness of market (caused) scarcity than of nonmarket scarcity.

In a replication and extension of his earlier study, Verhallen (1984) again manipulated the scarcity of recipe books as a within subjects variable and the cause of the scarcity as a between subjects variable. Subjects were asked to rank order the books twice -once from most to least preferred and once from most to least expensive. The preference rankings replicated those of the earlier study; subjects preferred the scarcer books when the scarcity was due to market causes but not when the scarcity was accidental.

The argument that market scarcity should produce stronger effects than does nonmarket scarcity was based on the assumption that only market scarcity would increase perceived expensiveness. The expensiveness ratings in Verhallen's (1984) replication partially support and partially disconfirm this expectation. Contrary to expectations, scarcity increased the perceived expensiveness of the books even when it was due to accidental, nonmarket causes. Apparently, some people's naive economic beliefs about scarcity are less sophisticated than I assumed they were. However, accidental scarcity produced a significantly smaller effect on perceived expensiveness than did scarcity caused by market forces. Thus, Verhallen's $(1982,1984)$ studies support the hypothesis that market scarcity has a bigger effect on assumed expensiveness and, hence, desirability than does nonmarket scarcity.

\section{Priming Thoughts about Price}

Research suggests that people do have a naive economic theory linking market scarcity with expensiveness. However, the salience of this belief almost certainly varies from person to person and from situation to situation. If this naive economic theory does play a role in scarcity's enhancement of desirability, then increasing the salience of this theory by priming thoughts about price should strengthen the effects of scarcity. 
Two experiments have tested this hypothesis (Lynn, 1987, 1989). In both studies, subjects were shown pictures of two oil paintings and were provided with information about the painting's title, the artist, and the availability of prints. Prints of one of the paintings were described as being available only from the French museum that houses the original, whereas prints of the other painting were described as being available from the French museum housing it and from most stores that carry art prints. Which of the two prints was described as available and which was described as unavailable was randomly varied between subjects. After viewing these stimulus materials, subjects: (a) rated the desirability of each print, (b) indicated how willing they would be to trade each print for the other, and (c) completed an availability manipulation check (which indicated the manipulation was successful).

The first of these two studies attempted to manipulate the salience of the subjects' naive economic theories about scarcity by describing the study as either a marketing study (high salience) or an attitude study (low salience) on the title page of the experimental booklet. Consistent with expectations, subjects rated the scarce print as significantly more desirable than the available print only when they thought they were participating in a marketing study. However, the Scarcity $x$ Prime interaction was not significant, and there were no reliable effects on subjects willingness to trade the prints.

Reasoning that the weak results of the first study were attributable to a weak priming manipulation, Lynn $(1987,1989)$ repeated the study with a more focused priming manipulation that subjects could not ignore. Prior to viewing the prints, subjects were asked to rate either the expensiveness of art prints in general (high-salience condition) or the desirability of art prints in general (low-salience condition). This study produced significant Scarcity X Priming Manipulation interactions on both the desirability and the willingness-to-trade ratings. Subjects thought the scarce print was more desirable than the available one and were less willing to trade the scarce print for the available one, but only under the expensiveness prime conditions. Consistent with the S-E-D model, priming thoughts about price strengthened scarcity's enhancement of desirability.

\section{Scarcity and Price Information}

If scarcity's enhancement of a product's desirability is mediated by assumed expensiveness, as depicted in the S-E-D model, then scarcity's effects should be weakened or eliminated by precluding people from assuming that the scarce commodity costs more than the available one. One way of accomplishing this is by informing people of the commodity's price. Thus, scarcity's enhancement of 
desirability should be weaker when people know how much the commodity costs than when they do not. Two experiments providing tests of this hypothesis are described next.

Szybillo (1973) presented female subjects with information about pant suits in a study with three levels of price (low price, no price information, and high price) and three levels of scarcity (low scarcity, no scarcity information, and high scarcity). Subjects then rated the pants suits on a number of dimensions. Analysis of subjects' desirability ratings revealed a scarcity main effect but not a Scarcity $\mathrm{x}$ Price Information interaction. Scarcity enhanced desirability in this study even when subjects knew how much the product cost.

In another study, I (Lynn, 1989) presented subjects with information about a white wine that was described as either scarce or available. In addition, subjects either were or were not informed about how much the wine cost. Subjects then rated the wine on a number of dimensions. Consistent with the mediating role of assumed expensiveness, scarcity reliably enhanced both the perceived expensiveness and the desirability of the wine only when subjects did not know how much it cost.

The fact that I (Lynn, 1989) found a reliable Scarcity x Price Information interaction supports the S-E-D model and raises questions about why Szybillo (1973) did not find such an interaction. One possibility is that the nature of the product in Szybillo's study may have made the price implications of scarcity less salient than the scarcity's uniqueness implications. Szybillo used women's fashion as the product in his study, and uniqueness is a critical attribute of fashions (Robinson, 1961). Thus, it is possible that fashions represent one class of products for which the S-E-D model is not applicable.

\section{Implications for Future Research}

\section{Methodological Implications}

The evidence that people's naive economic theories about scarcity can affect their evaluations of scarce products has methodological implications for researchers investigating need for uniqueness, reactance, and other explanations for scarcity's enhancement of desirability. Unaware of its potential impact, previous researchers have often employed cover stories, stimulus materials, and/or dependent measures that may have activated naive economic theories and hidden the other processes that were being investigated. For example, Atlas and Snyder (1978) failed to find a Scarcity x Need for Uniqueness interaction in a study that they described to subjects as marketing research. This story may have made the price implication of scarcity salient to subjects and, because low as well as high need for uniqueness subjects should have assumed the scarce products were more expensive, the activation of this naive economic theory may have weakened the study's Scarcity x Need for Uniqueness interaction. Similarly, 
Fromkin, Olson, Dipboye, and Barnaby (1971) failed to find a Scarcity x Possession interaction in a study that used recommended price as the dependent measure. This dependent variable may have activated the subjects' naive economic theories which, in turn, may have swamped reactance or other processes that might have otherwise produced a Scarcity X Possession interaction. To avoid these types of problems, researchers should do one or more of the following: (a) avoid cover stories that involve marketing or other economic concepts, (b) avoid using price as a measure of desirability, (c) manipulate nonmarket rather than market scarcity, and/or (d) specify the price of products when market scarcity is manipulated. These practices should minimize the interference of naive economic theories with other processes underlying scarcity's enhancement of desirability.

\section{Needed Research on the S-E-D Model}

The S-E-D model in Figure 1 hypothesizes that people will assume scarce things are expensive and that this assumed expensiveness will increase a scarce commodity's desirability by increasing its attributed quality and/or perceived status. The research reviewed here supports the first half of this model by demonstrating that (a) many people do associate scarcity with expensiveness, and (b) assumed expensiveness does mediate some scarcity effects on value. However, research is needed to test the second half of this model. Researchers have found that expensiveness increases the perceived quality and the status of products, but no one has tested whether or not these processes mediate scarcity's enhancement of desirability as hypothesized. This is clearly an important issue for future research on the S-E-D model to address.

Equally important is research on the boundary conditions of the S-E-D model. This model was presented only as a partial explanation for scarcity effects on desirability. Assumed expensiveness should mediate scarcity's enhancement of desirability only in some circumstances and only for some types of scarcity, people, and products. For example, market scarcity caused by resource shortages, deliberate marketing strategy, and/or unexpectedly high demand should all lead to assumed expensiveness, whereas nonmarket scarcity and market scarcity caused by a lack of demand should not lead to assumed expensiveness. More research is needed to test this expectation and to identify the situational factors, individual differences, and product categories that also define the boundaries of the S-E-D model's applicability.

\section{Additional Naive Economic Theories about Scarcity}

People have many naive economic theories; the belief that scarcity raises prices is just one of them (cf. Duncan, 1990). One potentially fruitful direction for future research is to identify and test 
other naive economic theories that may help explain scarcity's enhancement of desirability. Two possibilities seem particularly promising. First, some people may believe that scarcity is a direct indicator of quality. Often, high-quality, prestige products are produced in limited quantities, whereas low-quality imitations are mass produced. Thus, people may have learned to associate scarcity with quality. This suggestion is similar to Cialdini's (1985) claim that scarcity is a heuristic cue to value, but it has yet to be empirically tested. Some testable implications of this explanation are that scarcity should interact with involvement, the need for cognition, and the availability of other information about the scarce product, because people who are unable or unmotivated to process additional product information should be particularly prone to use peripheral cues like scarcity (cf. Petty \& Cacioppo, 1986).

A second promising topic for research is the possibility that people believe scarce products will appreciate in value more than available products will. People may assume that "if it is scarce today, it will be scarcer tomorrow," and this assumption may increase a scarce product's desirability to people seeking speculative investments, because increasing scarcity implies rising prices. This belief that limited supply increases future scarcity and price appreciation is reasonable in the case of collectibles and other nonreproducible goods, so naive economic beliefs about scarcity and appreciation may be particularly relevant for these types of products (see Stoller, 1984). Consistent with this reasoning are advertisements for collector's plates, which frequently stress both the limited supply of the plates and their potential for appreciation. These advertisements may both reflect and reinforce the public's belief that scarce collectibles are particularly good speculative investments. However, research is needed to demonstrate the existence of this naive economic theory and its role in scarcity's enhancement of desirability.

\section{Summary}

Although inconsistent with formal economic theory, scarcity's enhancement of desirability may be attributable to people's informal or naive economic theories. More specifically, people may desire scarce products more than available ones because they believe that scarce goods are: (a) expensive, (b) of high quality, and/or (c) good investments. Some evidence supporting the role of naive economic theories in producing scarcity's enhancement of desirability already exists, but these are largely untested explanations that offer many fruitful directions for future research.

\section{References}

Atlas, M. S., \& Snyder, C. R. (1978). The effects of need-for-uniqueness upon valuation of scarce and nonscarce objects. Unpublished honors thesis. University of Kansas, Lawrence. 
Brehm, J. W. (1966). A theory of psychological reactance. New York: Academic.

Brock, T. C. (1968). Implications of commodity theory for value change. In A. G. Greenwald, T. C. Brock, \& T. M. Ostrom (Eds.), Psychological foundations of attitudes (pp. 243-275). New York: Academic.

Cialdini, R. B. (1985). Influence: Science and practice. Glenview, IL: Scott Foresman.

Duncan, C. P. (1990). Consumer market beliefs: A review of the literature and an agenda for future research. In M. E. Goldberg, G. Gorn, \& R. W. Pollay (Eds.), Advances in consumer research (Vol. 17, pp. 729-736). Provo, UT: Association for Consumer Research.

Fox, K., \& Kehret-Ward, T. (1985). Theories of value and understanding of price: A developmental perspective. Advances in Consumer Research, 12, 79-84.

Fox, K., \& Kehret-Ward, T. (1990). Naive theories of price: A developmental model. Psychology \& Marketing, 7, 311-329.

Fromkin, H. L., Olson, J. C, Dipboye, R. L., \& Barnaby, D. (1971). A commodity theory analysis of consumer preferences for scarce products. Proceedings of the 79th Annual Convention of the American Psychological Association, 6, 653-654.

Furnham, A., \& Lewis, A. (1986). The economic mind. New York: St. Martin's.

Lea, S., Tarpy, R., \& Webley, P. (1987). The individual in the economy. Cambridge, England: Cambridge University Press.

Lynn, M. (1987). The effects of scarcity of perceived value: Investigations of commodity theory. Unpublished doctoral dissertation. The Ohio State University, Columbus.

Lynn, M. (1989). Scarcity effects on value: Mediated by assumed expensiveness? Journal of Economic Psychology, 10, 257-274.

Lynn, M. (1990). Choose your own price: An exploratory study requiring an expanded view of price's functions. Advances in Consumer Research, 17, 710-714.

Lynn, M. (1991). Scarcity effects on value: A quantitative review of the commodity theory literature. Psychology and Marketing, 8, 43-57.

Monroe, K. B. (1973). Buyers subjective perceptions of price. Journal of Marketing Research, 10, 70-80.

Murray, T. (1980). Developing the ability to relate scarcity and communication value: How children come to use products as linguistics units. Unpublished doctoral dissertation. University of Washington, Seattle. 
Olson, J. C. (1974). Cue properties of price: Literature review and theoretical considerations (Working paper series in marketing research. Vol. 20). State College, PA: The Pennsylvania State University.

Petty, R. E., \& Cacioppo, J. T. (1986). Communication and persuasion: Control and peripheral routes to attitude change. New York: Springer-Verlag.

Rao, A. R., \& Monroe, K. B. (1989). The effect of price, brand name and store name on buyers' perceptions of product quality: An integrative review. Journal of Marketing Research, 26, 351357.

Robinson, D. E. (1961). The economics of fashion demand. Quarterly Journal of Economics, 75, 376-385.

Seta, J. J., \& Seta, C. E. (1982). Personal equity: An intrapersonal comparator system analysis of reward value. Journal of Personality and Social Psychology, 43, 222-235.

Seta, J. J., \& Seta, C. E. (1992). Personal equity-comparison theory: An analysis of value and the generation of compensatory and noncompensatory expectancies [this issue]. Basic and Applied Social Psychology, 13, 47-66.

Snyder, C. R., \& Fromkin, H. L. (1980). Uniqueness: The human pursuit of difference. New York: Plenum.

Stacey, B. (1982). Economic socialization in the pre-adult years. British Journal of Social Psychology, 21, 159-173.

Stoller, M. A. (1984). The economics of collectible goods. Journal of Cultural Economics, 1, 91-104.

Szybillo, G. J. (1973). The effects of price and scarcity on the valuation of fashions by fashion opinion leaders and non-opinion leaders. Unpublished doctoral dissertation, Purdue University, Lafayette.

Veblen, T. (1965). The theory of the leisure class. New York: Kelly. (Original work published 1899)

Verhallen, T. M. M. (1982). Scarcity and consumer choice behavior. Journal of Economic Psychology, 2, 299-322.

Verhallen, T. M. M. (1984). Unavailability and the evaluation of goods: A behavioral economics approach in Scarcity: Unavailability and behavioral costs. Unpublished doctoral dissertation, Tilburg University, Tilburg, The Netherlands.

Wills, T. A. (1981). Downward comparison principles in social psychology. Psychological Bulletin, 90, 245271.

Yamauchi, K. T., \& Templer, D. I. (1982). The development of a money attitude scale. Journal of Personality Assessment, 46, 522-528. 